Chapter 5

\title{
The Role of Oxidative Stress in Melanoma Development, Progression and Treatment
}

\author{
Fabiana Henriques Machado de Melo, \\ Fernanda Molognoni and \\ Miriam Galvonas Jasiulionis \\ Additional information is available at the end of the chapter \\ http://dx.doi.org/10.5772/54937
}

\section{Introduction}

\subsection{Reactive oxygen species: An overview}

Oxygen free radicals or, more generally, reactive oxygen species (ROS) are products of normal cellular metabolism. They are well recognized for playing a contradictory dual role in living systems, sometimes deleterious sometimes beneficial, depending on cell type, genetic background and levels and types of species involved. Beneficial effects of ROS occur at low/ moderate concentrations and involve modulation of signaling pathways and gene expression regulation. The harmful effect of free radicals is termed oxidative stress and can result in damage to cellular lipids, proteins and DNA. The balance between benign and deleterious effects of ROS is a decisive factor of living organisms and is controlled by mechanisms called redox regulation. This process protects cells from oxidative stress and maintains the redox homeostasis by modulating the redox state in vivo [17].

ROS are a group of chemically reactive molecules derived from partial reduction of molecular oxygen, comprising a family of radical and non-radical species. A radical species is a free electron-containing species, including superoxide anion $\left(\mathrm{O}_{2}{ }^{--}\right)$and its conjugated acid hydroperoxyl radical $\left(\mathrm{HO}_{2}{ }^{--}\right)$, hydroxyl $(\bullet \mathrm{OH})$, carbonate $\left(\mathrm{CO}_{3}{ }^{--}\right)$, peroxyl $\left(\mathrm{RO}_{2}{ }^{\bullet}\right)$ and the alkoxyl radical $(\mathrm{RO} \bullet)$. Non-radical species, such as $\mathrm{H}_{2} \mathrm{O}_{2}$, hydrogen chloride $(\mathrm{HOCl})$, fatty acid hydroperoxides $(\mathrm{FaOOH})$, reactive aldehydes and singlet oxygen, can be readily reduced into free electron-containing species [18]. The reactivity of the different ROS with other compounds is variable and depends on their processing into more reactive $\mathrm{ROS}$ and the diffusion capability. It was shown that $\mathrm{O}_{2}{ }^{--}$and $\mathrm{H}_{2} \mathrm{O}_{2}$ do not exhibit strong reactivity with other bio- 
molecules, because they are more stable and can diffuse away from their sites of formation. Additionally, $\mathrm{H}_{2} \mathrm{O}_{2}$ can diffuse through membranes into the extracellular space. In the other hand, $\bullet \mathrm{OH}$ radical is highly reactive and probably accounts for most of the oxidative damage attributed to ROS. It half-live time is very short, approximately $10^{-9} \mathrm{~s}$, so $\bullet \mathrm{OH}$ produced in vivo reacts close to its side of formation. Iron regulation ensures that there is no free intracellular iron, however, in vivo, under stress conditions, an excess of superoxide releases "free iron" form iron-containing molecules. The released $\mathrm{Fe}^{2+}$ can participate in the Fenton reaction, generating highly reactive hydroxyl radical [19].

These reactive species are generated partly as by-products of cellular metabolism mainly during mitochondrial electron transport. Evidences implicating mitochondria as the principal source of ROS were based on the fact that isolated mitochondria can produce $\mathrm{O}_{2}{ }^{--}$through (1) auto-oxidation of the flavin component of complex I (NADH hydrogenase) and/or (2) autooxidation of the ubisemiquinone at complex III. During the process of cellular respiration, electron transfer occurs from $\mathrm{NADH}$ and FADH through complexes in the mitochondrial membrane, leading to a proton gradient, which is necessary for ATP production. Oxygen is involved as an electron acceptor at the end of the electron transfer in respiration chain. The electron transfer in respiratory chain is not completely efficient due electrons leakage from electron transport chain [20]. Approximately 1-3\% of the total oxygen consumed in aerobic metabolism produces $\mathrm{O}_{2}{ }^{--}$instead of contributing to the reduction of oxygen to water [18] Direct or indirect damage to mitochondria can lead to electrons leak from electron transport chain, including oxidative modification of mitochondrial membrane lipids (e. g. cardiolipin), resulting in mitochondrial outer membrane permeabilization. So $\mathrm{O}_{2}{ }^{--}$is continuously generated mainly at complex I and complex III due to transfer of electrons to molecular oxygen. Superoxide radical that is produced by complex I is released into the mitochondrial matrix, whereas complex III forms $\mathrm{O}_{2}{ }^{\circ}$ - both in the matrix and the inner mitochondrial space [21].

Another major source of ROS is NADPH oxidases, a family of membrane-bound enzymes that catalyze controlled production of $\mathrm{O}_{2}{ }^{--}$by coupling NADPH-derived electrons to oxygen. The NADPH oxidase complex consist of a membrane heterodimeric flavocytochrome (cytochrome B559) comprising two subunits, gp91phox and p22phox, and four cytosolic proteins, p47phox, p67phox, p40phox and the small guanosine triphosphate (GTP)-binding protein Rac (1 and 2) that form a functional complex at the membrane [22,23].

Superoxide can be also produced in the cell through one-electron transfer reactions catalyzed by a number of enzymes including monoamine oxidase, xantina oxidase, cyclooxygenases, lipoxygenases and components of the cytochrome P450 system. Peroxisomes are known to produce $\mathrm{H}_{2} \mathrm{O}_{2}$, but not $\mathrm{O}_{2}{ }^{\cdot-}$, under physiologic conditions [24]. Exposition to chemotherapeutic drugs and UV irradiation also increases the amount of ROS in intracellular milieu [25,26].

Redox homeostasis is determined by the balance between ROS production and detoxification rates by various antioxidants systems. To maintain intracellular free radicals from many sources under tight control, cells have developed a series of defense mechanisms against ROSinduced oxidative stress. The maintenance of intracellular redox state is essential for regulation of signal transduction because alterations in ROS levels can modify proteins conformation and consequently their functions. Enzymatic anti-oxidant defenses include superoxide dismutase 
(SOD), glutathione peroxidase (GPx), glutathione reductase (GPx) and catalase (CAT). Nonenzymatic antioxidants systems are represented by ascorbic acid (Vitamin C), carotenoids, flavonoids, glutathione (GSH), $\alpha$-tocopherol (Vitamin E), thioredoxin and other antioxidants. Superoxide dismutase converts $\mathrm{O}_{2}{ }^{--}$in the lesser reactive species $\mathrm{H}_{2} \mathrm{O}_{2}[18,27]$. There are three different SODs, which are involved in superoxide neutralization depending on the site of superoxide production or diffusion. $\mathrm{Cu}, \mathrm{Zn}$-SOD-1 is located in the cytoplasm, MnSOD-2 in mitochondria and $\mathrm{Cu}, \mathrm{Zn}-\mathrm{SOD} 3$ in the extracellular space [28]. When $\mathrm{H}_{2} \mathrm{O}_{2}$ is present in peroxisomes, it is decomposed to $\mathrm{H}_{2} \mathrm{O}$ and $\mathrm{O}_{2}$ by catalase. In the cytoplasm, glutathione peroxidase catalyzes the reduction of $\mathrm{H}_{2} \mathrm{O}_{2}$ into $\mathrm{H}_{2} \mathrm{O}$ via oxidation of glutathione [29, 30, 31].

The tripeptide glutathione is the abundant low-molecular-weight thiol antioxidant, constituting with thioredoxin, the major redox buffer of the mammalian cells. Glutathione is present in reduced (GSH) and in oxidized (GSSH) forms and the reduced form of glutathione is 10- to 100 -fold higher than the oxidized form. Glutathione couple (2GSH/GSSG couple) is the main responsible for the cellular redox homeostasis and therefore is a representative indicator of oxidative stress [17]. Because cellular glutathione concentration is $\sim 500$ - to 1000-fold higher than the other redox regulating proteins, changes in the ratio of reduced to oxidized glutathione reflect directly intracellular redox alterations [29]. The GSH/GSSG ratio is normally tightly regulated. Increased ROS levels result in an elevation of GSSH content, which is reduced to GSH by the NADPH-dependent glutathione reductase as well as thioredoxin/glutaredoxin systems. So, even in the presence of oxidative stress, the redox homeostasis can be maintained by increasing glutathione reductase activity or via elimination of GSSG from cells. Glutathione decreases intracellular ROS levels by acting as cofactor of several detoxifying enzymes against oxidative stress, e.g, glutathione peroxidase and glutathione transferase; participating in amino acid transport through the plasma membrane; regenerating vitamin $C$ and $E$ back to their active forms [32]. Glutathione also modulates the activity of thiol-dependent enzymes that contain cysteine residues sensitive to redox changes [33].The enzyme $\gamma$-glutamylcysteine synthase ( $\gamma$-GCS), involved in GSH synthesis, is regulated by ROS levels. Oxidizing conditions that result in GSH depletion promote a conformation change in $\gamma$-GCS, increasing its activity and GSH synthesis, while physiological GSH concentrations reduces GSH synthesis through feedback inhibition mechanisms [33].

Peroxiredoxins (Prxs) are also considered important cell redox state-regulating enzymes. Prxs are a family of peroxidases that also reduce $\mathrm{H}_{2} \mathrm{O}_{2}$ and alkyl hydroperoxides to the corresponding water or alcohol. At least six isoforms of human Prxs (Prx1-6) were located in different subcellular compartments, particularly in mitochondria (Prxs3 and 5). Prxs are maintained in the reduced form by the thioredoxin /thioredoxin reductase system that in conjunction with the GSH/GR system maintains the cellular thiol-disulfide redox status in the cell [34].

The thioredoxin system comprises thioredoxin (Trx), thioredoxin reductase (TrxR) and NADPH. Trxs are small redox active proteins (about 12kDa) with a disulfide active site (TrxS2) that is reduced to a dithiol (Trx- $(\mathrm{SH})_{2}$ ) by thioredoxin reductase (TrxR) using NADPH as electron donor. Mammalian Trx and TrxR are expressed as isoforms either in the cytosol and in the nucleus (Trx1 and TrxR1) or in mitochondria (Trx2 and TrxR2); in addition, there are 
testis-specific $\operatorname{Tr} x / \operatorname{Tr} x R$ system (Trx3 and TrxR3). Unlike $\operatorname{Tr} x$, which is reduced by its own reductase, glutaredoxins (Grxs) are coupled to GSH/GR. There are four Grx isoforms in humans, Grx1, Grx-3 and Grx5 primarily cytosolic and Grx2 displays different splice variants, which are located in mitochondria and nucleus [35].

There is a body of evidence showing the involvement of ROS in regulation of innumerous signaling pathways that control important biological processes, including migration, differentiation, proliferation, apoptosis, stress adaptation and gene expression. ROS can modulate multiple transduction signals by activation of growth factor receptors (e.g. the c-MET, EGF and PDGF receptor), activation of early growth-related genes such as c-fos and c-jun, alterations in the activities of protein kinases, oxidative inactivation of phosphatases and activation of transcription factors [36]. In the other hand, increased ROS levels in tumor cells is influenced by numerous factors such as disrupted signaling pathways, altered expression of transcription factors, deregulation of antioxidant enzymes, mitochondrial dysfunction, aberrant cancer cell metabolism, alteration in proliferation and the acquisition of the metastatic phenotype $[9,37]$.

Redox regulation of signaling pathways occurs through modifications of redox-reactive cysteine residues on proteins, which depend on redox status of the cell and the concentration of ROS. Oxidation of these residues forms reactive sulfenic acid (-SOH) that can form disulfide bonds with nearby cysteine (-S-S-) or undergo further oxidation to sulfinic $\left(-\mathrm{SO}_{2} \mathrm{H}\right)$ or sulfonic $\left(-\mathrm{SO}_{3} \mathrm{H}\right)$ acid. These alterations induced by ROS modify the structure and activity of proteins, regulating their functions. These redox modifications are reversible by antioxidants systems, including thioredoxin and peroxiredoxin, contributing to the modulation of signal transduction [8].

\section{Reactive oxygen species in cancer development}

Since ROS can act as signaling molecules it is reasonable to think that depending on cell context ROS could participate in development of innumerous pathologies including cancer. There is accumulating evidence supporting this view. Levels of ROS are increased in many tumors and murine and human tumor cells lines, contributing to neoplastic transformation and tumor progression [13, 38, 39, 40]. By regulating signal transduction pathways, ROS is involved in the acquisition of cancer hallmarks including self-sufficiency in growth signals, insensitivity to growth inhibitory (anti-growth) signals, evasion of programmed cell death (apoptosis), limitless replicative potential, sustained angiogenesis, tissue invasion and metastasis, altered metabolism and inflammation [40,41]. The accumulation of ROS participates in the tumor development of many types of cancer including melanoma, leukemia, gastric, prostate, breast and colon cancer $[39,42,43,44,45]$.

One of the signaling pathways regulated by ROS that is implicated in oncogenic transformation is the mitogen-activated protein kinase (MAPK) cascade that consists of four major MAPKs: the extracellular signal-related kinases (ERK 1/2), the c-Jun N-terminal kinases (JNK), the p38 kinase (p38) and the big MAP kinase 1 (BMK1/Erk5). The apoptosis signal-regulated kinase 1 (ASK1), which regulates the JNK and p38 MAPK pathways, is activated under stress conditions 
by dissociation of the redox protein thioredoxin. ASK1 is activated when ROS oxidize two cysteine residues in the redox center of thioredoxin, inducing formation of an intramolecular disulfide bond and triggering this dissociation from ASK1 [8]. Activated p38 negatively regulates the malignant transformation induced by oncogenic H-Ras by inhibition of ERK pathway, induction of premature senescence or by cell cycle arrest triggered by p53 [46]. In fact, it was shown that p38 specifically impairs the malignant transformation induced by oncogenes that increase ROS levels (including Ras) by triggering apoptosis and decreasing the accumulation of ROS [47]. MAPK pathways are also activated by the direct inhibition of MAPK phosphatases by ROS. Downregulation of mitogen-activated protein kinase phosphatase (MKP)-3, a negative regulator of ERK1/2, was associated with ubiquitination/proteosome degradation mediated by high intracellular ROS accumulation such as hydrogen peroxide. The aberrant ERK activation contributes to tumorigenicity and chemoresistance of human ovarian cancer cells [48].

Another signaling pathway that contributes to malignant phenotype acquisition, participating in cell survival and proliferation, is the phosphoinositide 3-kinase (PI3K) pathway. Activation of this signal transduction is regulated by the phosphatase and tensin homology (PTEN) phosphatase. It was found that PI3K pathway is reversible regulated by the redox status of the cell by inactivation of PTEN through oxidation of the cysteine located in its catalytic domain [8].

ROS have also been implicated at all stages of the carcinogenic process since are capable of modulating gene expression through oxidative DNA damage and epigenetic alterations [38, 50]. ROS-induced DNA damage includes single- or double-stranded DNA breaks, purine, pyrimidine or deoxyribose modifications and DNA cross-links. DNA damage can result in arrest or induction of transcription, induction of signal transduction pathways, replication errors and genomic instability, all of which are associated with tumorigenesis [19, 51]. The most extensively studied DNA lesion is 8-OH-G, a potential biomarker of carcinogenesis [50]. This oxidative DNA lesion was shown to interfere in the binding of methyl binding proteins to 5-methylcytosines [52], and 8-OH-G located adjacent to the target cytosine can affect the affinity of DNA for DNMT3A [53]. These data indicate that 8-OH-G may play a role in the formation of aberrant DNA methylation patterns during tumor formation. Increased Dnmt1 and global DNA methylation levels were observed in murine melanocytes submitted to sustained stress condition associated with malignant transformation [38]. Increased ROS levels can also induce the recruitment of DNMT1 to damaged chromatin where, together with DNMT3B and members of the Polycomb repressive complex 4, they form a silencing complex in GC-rich areas that might explain cancer-specific aberrant DNA methylation and transcriptional repression [54]. Oxidative stress associated with inflammation also triggers redox signaling through inactivation of HDACs. The reduction of HDAC activity is associated with posttranslational modifications, such as carbonylation [55]. Together, these data suggest a connection among oxidative stress, DNA damage, epigenetic alterations and malignant transformation.

Chronic stress conditions in tumor cells are triggered by an imbalance between ROS production and the ability of cells to scavenge these species. Many studies have shown the increase in Nox expression and activity in transformed cell lines [9, 56, 57]. It was shown that constitutively activated isoform of p21 ${ }^{\text {Ras }}, \mathrm{H}-\mathrm{Ras}^{\mathrm{v} 12}$, in NIH-3T3 fibroblasts improved increased 
superoxide anion production by Nox1, and was functionally required for oncogenic Ras transformation [58]. Mitochondria dysfunction can lead to oxidative stress, which could be also implicated in cancer development. Besides defects in mitochondrial electron transport chain and prolonged hypoxia and glucose deprivation, disrupted cell signal transduction can also increase mitochondrial-derived ROS in cancer cells. In turn, alteration in mitochondrial bioenergetics modulates signal transduction. It was demonstrated that increased ROS production derived from mitochondria is induced by oncogenic $\mathrm{K}-\mathrm{R}$ as and is required to maintain anchorage-independent cell grow and proliferation [59].

Increased ROS levels in malignant cells can arise also from the alteration or inactivation of the antioxidant defense system. Low activities of CuZn-SOD, Mn-SOD, CAT and GPxs have been reported in a variety of transformed and malignant cells compared with their normal counterparts [19]. Decreased activity and expression of Mn-SOD was reported in melanoma, colorectal, prostatic and pancreatic carcinomas [19].

However, it is important to note that only under a mild elevation in intracellular $\mathrm{O}_{2}{ }^{--}$and $\mathrm{H}_{2} \mathrm{O}_{2}$ signaling pathways stimulate proliferation. In the other hand, if the concentration of ROS in the cells is so high these effects can be completely reversed resulting in oxidative stress and death. In this way, cancer cells must render the intracellular milieu pro-oxidant, where ROS has a pro-life role [60], which is supported by the fact that MnSOD acts like a tumor suppressor gene. Many authors have shown the suppression of malignant phenotype after MnSOD reexpression [61, 62, 63]. In addition, intracellular $\mathrm{O}_{2}{ }^{-}$- has the ability to regulate apoptosis sensitivity to a variety of apoptotic stimulus $[12,13]$. The inhibitory effect of $\mathrm{O}_{2}{ }^{-}$- on cell death signaling can be attributed to caspase proteases, mediators of apoptotic signaling, inactivation by oxidative modifications [60] and by the increased expression of $\mathrm{Bcl}-2$, which is associated with a pro-oxidant milieu [64].

\section{Melanoma and oxidative stress}

Cutaneous melanoma is a highly malignant tumor derived from pigment-producing melanocytes in the epidermis of the skin. Melanocytes are responsible for the synthesis of melanin in melanosomes, which in turn, is transferred to neighboring keratinocytes where it can protect DNA from UV radiation damage. Melanocytic transformation is triggered by sequential accumulation of genetic and epigenetic alterations that driven modifications in several genes and signaling transduction pathways leading to abnormal proliferation of melanocytes.

Melanoma is one of the most aggressive tumors with a high frequency of metastasis. The incidence and mortality rates of malignant melanoma have increased in the past few decades particularly in Europe and the United States. Although, the etiology of melanoma is not completely known, several molecular and cellular mechanisms have been shown to contribute to melanoma genesis. Chronic stress exposures induced, for example, by solar UV and inflammation are among risk factors for melanoma development [65,66].

Many authors have shown increased ROS levels in melanoma cells through multiple mechanisms $[9,12,57]$. It was also demonstrated that the ability of melanocytes and melanoma cells to 
respond to oxidative stress is different. While melanocytes have the capability of suppressing increased ROS levels, melanoma cells are unable to do that [67]. This redox imbalance has a central role in melanoma genesis. One of the reasons is that melanoma cells show decreased antioxidant capability characterized by reduced catalase, glutathione-S-transferase and MnSOD enzymatic activity and low levels of glutathione [68, 69], characterizing an aberrant redox state. Moreover, melanoma cells have constitutive abnormalities in their melanosomes [70]. More importantly, it was found that melanoma cells have increased superoxide anion and decreased hydrogen peroxide levels leading to an establishment of a pro-oxidant intracellular milieu and the activation of redox-sensitive transcription factors that enhance the aggressiveness seen in melanoma cells characterized by high proliferative rate and drug resistance [60].

Besides genetic alterations found in melanoma caused by UV, the involvement of ROS in epigenetic alterations was also described in melanoma cells. Increased Dnmt1 and global DNA methylation levels was observed in murine melanocytes submitted to sustained stress condition associated with malignant transformation [38]. The treatment of cells with superoxide anion scavenger abrogated the increase of both Dnmt1 and global DNA methylation level (unpublished results).

\section{UV radiation, its connection with oxidative stress and melanoma development}

Circumstantial and direct evidences show ultraviolet radiation (UVR) as major environmental risk factor for melanoma formation. One of the evidences is the fact that melanoma incidence is higher in population with light skin types [71]. Skin types depend on melanin production and there are two types of melanin, eumelanin and pheomelanin. People with light skin have more pheomelanin than eumelanin and it has been shown that eumelanin confers more protection against malignant melanoma [72,73]. Melanin is an important chromophore in the skin which is able to absorb UVR, visible light and scavenge molecular oxygen and hydroxyl radicals, protecting DNA from adducts formation and breaks [4]. In addition, melanoma from sun-exposed areas has different gene mutations than melanoma from unexposed skin areas, suggesting the existence of a particular pathway in melanoma genesis associated with UV radiation [65].

Ultraviolet radiation is subdivided into long wavelength UVA, shorter UVB and shortest UVC. UVC is normally absorbed by ozone at atmosphere and generally does not reach human skin. UVB is absorbed by cells located at outermost layer of epidermis and can be directly absorbed by keratinocytes DNA, causing its damage by producing photoproducts such as cyclobutane pyrimidine dimmers [74]. Additionally, UVB can affect DNA indirectly through oxidative stress generation [75]. In other way, UVA radiation can penetrate deeper into skin and, in addition to be absorbed by keratinocytes, is also absorbed by melanocytes, dermal fibroblasts and other cell types [76]. UVA comprises the majority of UV radiation that reaches earth's surface (95\%) and is poorly directly absorbed by DNA, but can indirectly affect DNA by causing reactive oxygen species (ROS) increase and oxidative stress [77]. Oxidative stress can 
lead to single and double strand DNA breaks, DNA adducts formation, as well lipids and protein peroxidation.

The specific contribution of UVB and UVA radiation to melanocytes malignant transformation is questionable because the majority of in vivo and in vitro studies focus on UVB radiation. Several studies in mice that develop malignant melanoma show a role of UVB in melanoma genesis, in contrast to this, the role of UVA is less clear. It has been demonstrated that UVB can activate an important differentiation and proliferation signaling pathway, the MAPK pathway, leading to AP1 translocation to nucleus [2]. AP-1 results from heretodimerization of c-Fos and c-Jun proteins, and this complex is important for proper induction of many genes involved in cellular damage protection and repair against ROS damage. This transcriptional factor can operate as an oncogene and it has been related with tumor drug resistance [78, 79]. Additionally, Ming and co-workers [81] showed that UVB radiation induces PTEN down regulation through ERK and AKT pathway activation. The phosphatase and tensin homolog PTEN is an important tumor suppressor gene that negatively regulates PI3K/AKT pathway and its loss is related with many tumors, including melanoma [81, 82, 83]. In contrast with these studies, Kabuyama and colleagues showed in 2001 that while c-Jun is activated in cells irradiated with UVB, ERK activation occurs at same cells only after UVA irradiation [2]. Interestingly, treatment with antioxidants was able to reverse such activations.

When compared to UVB, there are fewer studies showing long-wave UVA radiation role in skin cancer, including melanoma. Recent study in mice did not show an induction of melanoma by a single UVA dose [84]. Nevertheless, there are circumstantial evidences suggesting UVA role in melanoma formation once it gets through clothes in greater quantities than UVB and it comprises the majority of UV radiation. Moreover, UVA, like mentioned before, can penetrate deeper into skin than UVB. It has been shown that high UVA dose causes loss of reduced glutathione and reduces plasma membrane stability in human melanocytes [85]. Glutathione is an important cell antioxidant and loss of its reduced state may reflect the oxidative pressure within this melanocytes as well the plasma membrane stability, once oxidative stress can cause lipid peroxidation. In opposite way to this effect of UVA on melanocytes, this has only been shown before in keratinocytes after UVB irradiation [85]. In addition, a recent work showed an alternative role of melanin in mitochondrial DNA damage only during UVA irradiation, not UVB, providing evidences for dual role of melanin as both protector and damage agent [86]. The accumulation of mitochondrial DNA (mtDNA) mutations, through oxidative stress mechanisms, has been proposed to contribute to carcinogenic and aging process in many tissues, including skin $[76,86]$.

Regarding the link between UV radiation and oxidative stress in melanoma, it is important to mention the fact that both UVA and UVB irradiation can induce nitric oxide synthases (NOS) expression at skin $[87,88,89]$. Warren and colleagues showed, for example, that an intradermal injection of L-NAME (NOS inhibitor) prevented erythema caused by UV radiation exposition in rats [87]. In addition, nitric oxide in combination with superoxide anion can form peroxynitrite, which leads to lipids and proteins peroxidation. Additionally, peroxynitrite might oxidize tetrahydrobiopterin (BH4) NO syntases' cofactor, what could cause NOS uncoupling. A critical aspect of NOS function is the requirement for the cofactor $\mathrm{BH} 4$, its absence destabilize NOS, 
which becomes "uncoupled". Uncoupled NOS produces superoxide anion instead of nitric oxide [12]. NOS-dependent superoxide formation has central role in the pathology of vascular diseases like diabetes, hypertension and atherosclerosis, but less is known about this phenomenon in cancer $[90,91]$. Nevertheless, results from our group showed for the first time the involvement of the uncoupled eNOS in the generation of superoxide in melanoma genesis [12].

As showed, a potential causative role of ultraviolet radiation in oxidative stress and melanoma genesis has been investigated; however, more studies are necessary to fully understand this association.

\section{UV-induced inflammation, immunosuppression and melanoma}

The exposure of skin to UV irradiation results in increased blood flow, infiltration by macrophages and neutrophils, as well higher levels of nitric oxide and prostaglandins [87, 92]. This phenomenon is clinically observed as inflammation. Other UV-induced mediators such as tumor necrosis factor (TNF) and interleukin-1 $\alpha$ (IL-1 $\alpha)$ also contribute to inflammation. The recruited inflammatory cells produce ROS that, like mentioned before, drive damage to lipids, proteins and DNA. This damage could lead to genetic and epigenetic alterations and contribute to cancer development $[38,93,94]$. ROS and NO can be associated with all steps of tumor progression, causing oncogene activation, tumor suppressor inhibition through mutations or aberrant epigenetic modifications, angiogenesis, local invasion and metastasis [95].

Another feature of UV radiation is the fact that it can cause local and systemic immunosuppression on skin. The precise mechanism is not fully elucidated, but DNA damage is regarded as fundamental inciting event, which leads to depletion of Langerhans cells from epidermis, interfering with antigen recognition $[96,97]$. It was observed that immunosuppression induced by UVA radiation diminishes immune surveillance and allows cutaneous melanoma development in transgenic mice [84]. Some additional evidences suggest that NO might be involved in passing a "migration signal" to the Langerhans cells that stimulates them to migrate and leave epidermis [98]. In this way, nitrosative stress could be involved both in inflammation and immunosuppression mechanisms linked with carcinogenesis.

\section{The role of NADPH oxidase enzymatic complex in melanoma genesis}

Melanoma cells spontaneously generate ROS and present alteration in NOX expression. NOX family, that comprises NOX1, NOX2 (also called gp91), NOX3, NOX4 and NOX5, consists of catalytic subunit of NADPH oxidase enzymatic complex, one of cells' superoxide anion sources, as mentioned before. The active form of this multi-protein complex is also normally composed by transmembrane $p 22^{\text {phox }}$ and cytosolic proteins, $p 40^{\text {phox }}, p 46^{\text {phox }}, p 67^{\text {phox }}$ and Rac. It has been observed that while melanoma cells present NOX2, $p 22^{\text {phox }}$, p67 ${ }^{\text {phox }}$ and NOX4 expression, epidermal melanocytes express only $p 22^{\text {phox }}$ and NOX4 [99]. Moreover, NOX4, that does not present Rac cytosolic subunit, was found up regulated in several melanoma cell lines and it 
seems to be important to regulation of G2-M cell cycle progression [57]. Interestingly, Govindarajan and co-workers [9] showed that AKT signaling is responsible by NOX4 overexpression in melanoma cell line WM35. These authors also observed that these events seem to be necessary to conversion of melanoma with radial growth to melanoma with vertical growth behavior. In addition to NOX4 role in melanoma, recent research paper showed increased NOX1 protein level and activity in melanoma cell lines compared to melanocytes. The same work showed that NOX1 overexpression increases melanoma cells invasion on matrigel and stable clones overexpressing Nox1 exhibited epithelial-mesenchymal transition [100].

There are few studies about NOX role in melanoma and more studies in this area may elucidate how NADPH oxidases might regulate specific signaling pathways during melanocyte malignant transformation and melanoma progression.

\section{Mitochondria dysfunction as a ROS source in melanoma and therapeutic target}

Recently, the role of mitochondrial functions, such as redox regulation and oxidative phosphorylation in melanoma progression has become to be elucidated. It was shown that dysfunctional mitochondria affect melanoma cell survival and death and drug resistance [101]. Tumor cells normally produce ATP via glucose metabolism with concomitantly decrease in ATP production by oxidative phosphorylation [102]. Unlike most tumor cells, melanoma cells rely more on oxidative phosphorylation than glycolysis to produce ATP. Compared with solid tumor xenografts, human melanoma xenografts have one of the highest rates of oxygen consumption, a surrogate marker of oxidative phosphorylation [101, 103]. Moreover, non-glycolytic metabolic sources, such as the Krebs cycle, occur more frequently in melanoma cells compared with melanocytes [104]. It was also shown that a particular group of patients with advanced melanoma utilize oxidative phosphorylation for energy production in addition to glycolysis [105]. Consequently, the mitochondria of melanoma cells generate high levels of ROS. These features make mitochondria a potential chemotherapy target in melanoma. In fact, it was shown that the drug Elesclomol, that alter redox balance and induce oxidative stress, lead to melanoma cells apoptosis by inhibiting oxidative phosphorylation through down regulation of proteins from electron respiratory chain. In addition, it was also demonstrated that melanoma cells

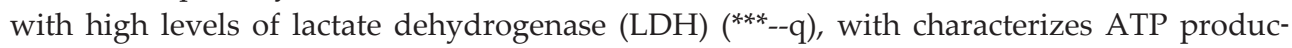
tion mainly by glucose metabolism, are more resistant to Elesclomol [101]. Analysis of patients with normal lactate LDH versus patients with high serum LDH levels showed that the increase in LDH levels is a prognostic factor for metastatic melanoma [106].

\section{Melanin: A pro-oxidant molecule contributing to melanoma genesis}

In normal melanocytes, melanin is generated from the successive oxidation of tyrosine by tyrosinase in sub organelles called melanosomes to protect DNA, including mitochondrial 
DNA, from UV radiation-induced damage [86]. Moreover, melanin neutralizes the inflammatory response to radiation and acts like an antioxidant, suppressing superoxide anion, singlet oxygen and hydrogen peroxide [107]. However, in melanoma cells, melanogenesis itself is a source of ROS and oxidative stress because of malformed melanosomes and melanin synthesis disruption [108]. Therefore, depending on the melanin type and redox intracellular state, melanin can play a dual role, both as a photoprotector and as a photosensitizer [86]. In melanoma cells, melanosomes are poorly compartmentalized, with malformed or twinned membranes, occlusions within the melanin and evident fragments outside of melanosome [109]. The structural differences between melanosomes from melanocyte and melanoma cells are significant, as melanosomal compartmentalization protects the cell from the highly reactive small-molecules catechols that are generated as by products during melanogenesis [108]. Ultrastructural studies of human melanosomes also indicate that melanocytes generally have fewer melanosomes than malignant melanoma [110]. Melanin deregulation renders it a prooxidant with ability to increase ROS levels and damage DNA [111]. In addition, melanin exposition to radiation also renders it pro-oxidant [107]. It is important to note that disturbed melanin synthesis and chronic oxidative stress are present in dysplastic nevi, indicating that the switch of melanin to a pro-oxidant state occurs early in melanoma development [112].

Melanins are naturally associated with a number of metal ions and have the capability to accumulate metals. However, oxidized melanin has high affinity for metal ions in vivo and the binding of metal ions alters dramatically chemical properties of melanin, increasing it susceptibility to further oxidation and the rate of melanin bleaching [113]. Therefore, it was suggested that metals ions are associated to melanin conversion from a normal reducing status to a pro-oxidant state. The binding of divalent zinc or cooper to melanin increases the capability of melanin to react with oxygen by redox cycling and induces the increase in superoxide and hydroxyl radicals [113]. There are several studies implicating heavy metal ions, including zinc, cooper and cadmium, in the pathogenesis of melanoma [112, 114]. In fact, melanoma tumors accumulate high concentrations of $\mathrm{Cu}$ and other metals in comparison with melanocytes, which induce oxidative stress [115]. Moreover, $\mathrm{Cu}$ is a critical cofactor for the enzyme tyrosinase and is found in abundance in melanosomes from melanocytes and melanoma cells [107]. It was shown that the pro-oxidant state of melanin can be a selective target in melanoma. The treatment of melanoma cells with $\mathrm{Zn}$ and $\mathrm{Cu}$ dithiocarbamate complexes, which are known to increase the uptake of metal ions into the cell, augmented the redox cycling of melanin and the oxidative stress, leading melanoma cells to apoptosis. Interestingly, the treatment was less toxic to melanocytes [113].

Melanin synthesis is regulated mainly by the alpha-melanocyte stimulating hormones $(\alpha-$ $\mathrm{MSH})$, which bind to the melanocortin 1 receptor (MC-1R) and activate the cAMP pathway, which in turn, triggers its downstream effector molecules Protein Kinase A (PKA) and cAMPResponsive Element Binding (CREB) transcription factors to up-regulate the expression of microphtalmia-associated transcription factor (MITF). MITF induces the transcription of tyrosinase, the rate-limiting enzyme in the synthesis of melanin [116]. Recently, it was shown that melanin synthesis is regulated by Nox4-induced ROS in a feedback mechanism regulated by MITF signaling pathway in melanoma cells [37]. The expression of Nox4 and ROS produc- 
tion was increased by $\alpha-\mathrm{MSH}$ and was dependent of MITF signaling. Expression silencing of Nox4 gene increased melanin formation through MITF and tyrosinase activation upregulation, unraveling a novel negative regulatory mechanism of pigmentation in melanoma cells. This could be an adaptive mechanism of melanoma cells submitted to chronic stress condition to maintain redox homeostasis: decreasing oxidative stress by inhibiting the synthesis of pro-oxidant melanin.

\section{Uncoupled endothelial nitric oxide synthase as a superoxide anion source: Its role in melanocyte transformation and melanoma progression}

There is a lot of evidence showing the involvement of inducible nitric oxide synthase (iNOS) in melanoma development. Its strong association with poor patient survival seems to indicate that iNOS is a molecular marker of poor prognosis or a putative target for therapy. All these studies show the role of nitric oxide, a free radical produced by NOS, in proliferation and apoptosis $[118,119]$. Recently, the role of NO derived from eNOS in melanoma induced by chronic stress was shown [117]. In fact, eNOS-- mice are resistant to tumor development [120, 121]. However, NOS can be also a source of superoxide anion [10, 11].

It has been extensively demonstrated that uncoupled NOS can generate superoxide, which has a central role in the pathogenesis of vascular diseases, such as diabetes, hypertension and atherosclerosis. NOS are homodimeric oxidoreductases that catalyze NO production from Larginine guanidine nitrogen using molecular oxygen. The NOS reductase domain generates electron that flow from NADPH through FAD and FMN flavins and are transferred to the oxidase domain of the other monomer in which L-arginine oxidation occurs at the heme group in the active site. A critical aspect of NOS function is the requirement of the cofactor tetrahydrobiopterin (BH4). In its absence, NOS dimerization is lost and NOS catalytic activity becomes uncoupled. In this state, NADPH oxidation and molecular oxygen reduction are uncoupled from L-arginine hydroxylation and nitric oxide (NO) formation. However, electron transfer from NADPH to molecular oxygen is not inhibited, resulting in superoxide production $[10,11]$.

An in vitro murine melanocyte malignant transformation model was developed in our laboratory after submitted a non-tumorigenic melanocyte lineage, melan-a, to a chronic stressful condition [122], which resulted in the establishment of pre-malignant and melanoma cell lines. It was demonstrated that along tumor progression increased superoxide and decreased NO levels were produced. The treatment with L-sepiapterin, a BH4 precursor, decreased superoxide and increased NO levels in melanoma cells [12]. The abrogation of superoxide anion levels rendered melanoma cells less anoikis-resistant. More importantly, LNAME, a NOS inhibitor that decreases superoxide anion levels, impaired the acquisition of a malignant phenotype by melan-a that was subjected to a sustained stressful condition [12, 38]. Moreover, the expression of GTP cyclohydrolase I, the rate-limiting enzyme in the synthesis of $\mathrm{BH} 4$, is decreased in melanoma cells (unpublished results). Together, these data show that the superoxide production by eNOS uncoupling may be important for melanoma 
cells survival and melanocyte malignant transformation. The possible use of BH4 as a chemopreventive agent for melanoma development is under investigation in our laboratory.

\section{Redox signaling in melanoma}

The appropriate proceeding of tumor cells exposed to ROS is associated with activation of different signaling pathways that in turn regulate transcriptional changes that allow cells to respond and adapt to oxidative stress for maintenance of homeostasis. These alterations are regulated by redox sensors such as apurinic/apyrimidinic endonuclease (APE-1/Ref-1). APE/ Ref-1 is a point of convergence for various redox-sensitive signals as well as being important in DNA repair. Many studies demonstrated that many survival, proliferation and antiapoptotic signaling pathways are activated by APE/Ref-1-mediated transcription factors, such as AP-1, NF- $\kappa \mathrm{B}, \mathrm{HIF}-1 \alpha$ and $\mathrm{p} 53$, whose regulation occurs in both a redox-dependent and a redox-independent manner [36]. Elevated APE/Ref-1 was associated with decreased intracellular ROS levels as well as reduced oxidative DNA-damage lesions. However, the prolonged activation of APE/Ref-1 induced by a sustained stress condition, switches the cellular signaling to proliferation and apoptosis resistance. It was shown that increased expression of APE/Ref-1 and increased ROS levels play a role in malignant transformation by increasing anchorageindependent growth and colony formation [123]. Moreover, knockdown of APE/Ref-1 was shown to efficiently induce apoptosis, sensitization, or both to chemical treatments [124]. It is also well documented that elevated APE/Ref-1 is associated with chemo- and radio-resistance in a number of cellular systems. Recently, this group also suggested that APE/Ref- 1 is involved in the regulation of metastasis produced by melanoma cells [125]. These studies suggested that, as an adaptive response induced by APE/Ref-1, this transcription factor besides efficiently repairs oxidative DNA damage, also regulates redox-sensitive signaling such as AP-1 and NF$\kappa \mathrm{B}$, which are involved in melanoma genesis. In fact, it was demonstrated the increased expression of APE/Ref-1 in melanoma specimens and cells, which is predominantly found in the nucleus and contributed to the binding and activation of AP-1 and NF- $\kappa B$ [123, 124]. Therefore, all these properties make APE/Ref-1 a promise target for melanoma therapy.

A signaling pathway disrupted in melanoma cells that is redox-sensitive is the Ras/ BRAF/MEK/ERK [126]. We have observed that activation of Ras-ERK signal transduction in melan-a melanocytes during loss of integrin-mediated cell-matrix contact is regulated and regulates superoxide anion levels which is associated with global DNA hypermethylation (unpublished results). This aberrant signaling seems to have a significant impact in melanoma genesis since the malignant transformation was drastically compromised when melan-a melanocytes were pre-treated with superoxide scavenger.

Another pathway involved in melanoma progression that is responsive to alterations in redox homeostasis is p38 signal pathway. In melanocytes exposed to oxidative stress and UVirradiation, p38 is activated and induces the expression of $\mathrm{p} 16 \mathrm{I}^{\mathrm{NK} 4 \mathrm{~A}}$, which in turn decreases ROS levels [127]. It can be a mechanism by which the tumor suppressor gene $\mathrm{p} 16^{\mathrm{INK} 4 \mathrm{~A}}$ protects melanocytes against malignant transformation. According to this point, it was shown by many authors that induction of apoptosis in melanoma cells is dependent on p38 activation [128, 129]. 


\section{Antioxidant therapy for melanoma}

Many cancer types have some imbalance in physiologic antioxidant levels compared with the cell of origin like was mentioned before in this chapter [130]. Moreover, levels of anti-oxidant enzymes and non-enzymatic antioxidants such as catalase, MnSOD, glutathione (GSH), vitamins E, C and A are all typically decreased in tumors [131]. Although mutations in MnSOD gene have been demonstrated in some melanomas, the other antioxidant enzymes were found with high activity in this type of cancer cells [61, 131].

The redox imbalance found in melanoma cells is implicated in the malignant phenotype of these cells, characterized by abnormal proliferation, apoptosis resistance and metastasis capability through regulation of key signaling pathways. These observations support the notion that melanoma could be targeted using antioxidant therapy.

One of antioxidants, approved by Food and Drug Administration (FDA) and used to treat pulmonary fibrosis, is N-acetylcysteine (NAC) [132]. Studies in mouse showed that orally administrated NAC reduced UV-induced squamous carcinoma [133]. Moreover, Cotter and colleagues showed that NAC protects melanocytes from oxidative stress and delays UVinduced melanoma growth in mice [134]. In addition, other studies observed that topical NAC reduced UV-mediated GSH depletion and peroxide induction in normal human skin [135, 136]. The antioxidant vitamin E delays or reduces UV-induced skin carcinogenesis in mice, through reduction in DNA damage, immunosuppression or both [137]. Other epidemiologic studies showed that increased vitamins D and C intakes have some influence in melanoma prevention [14].

As mentioned above, the redox transcription factor sensor APE/Ref- 1 has a potential as a target for the development of a new chemopreventive agent against cancer. Using docking-andscoring technology and virtual screening, resveratrol was found to dock in one of the two drugtreatable pockets located in the redox domain of APE/Ref-1 [124]. The inhibitory effects of resveratrol on APE/Ref-1 occurred mostly through its redox-regulating functions and might be the principal role on its pharmacological activities, which are implicated in the reduced AP-1 and NF- $\kappa B$ activities in many human cancers [138]. In studies using human melanoma cells, resveratrol was shown to inhibit, in a dose-dependent manner, the APE1/Ref-1-mediated DNA-binding of AP-1. Resveratrol was also shown to inhibit APE1/Ref-1 endonuclease activity and render melanoma cells more sensitive to treatment with the alkylating agent dacarbazine [124]. More recently, a small molecule called E3330 was developed and showed strong inhibition of APE/Ref-1 in vitro [139]. The use of E3330 inhibited the interaction between retinoic acid receptor and its DNA response elements, which is redox-sensitive and mediated by APE/Ref-1, and increased the differentiation and apoptosis of myeloid leukemia cells induced by retinoic acid [140]. Therefore, these compounds may represent a novel class of anticancer agents and promising candidates for in vivo studies.

Although promising, treatment of melanoma with antioxidants has not yet achieved the desired results. One hypothesis is that antioxidants can be used as chemopreventive drugs, since the main role of ROS seems to be in the early progression of melanoma, when the tumor is fully installed. 


\section{Conclusion}

Melanocytes are naturally exposed to oxidative stress due to UV, UV-associated inflammation and metal ions accumulation. However, melanocytes have a great capability to regulate their redox homeostasis due increased antioxidant activity and redox buffer characteristic of melanin. The disruption of redox regulation in melanocytes is not clear, but seems to be a consequence of many factors, including decreased of antioxidant enzymes expression and activity as MnSOD and glutathione levels, the switch of melanin to a pro-oxidant molecule and disturbance of signaling pathways that control melanocytes proliferation. Therefore, increased ROS levels found in melanoma cells are not a simple consequence of altered metabolism, but instead seem to have a central role in melanocyte malignant transformation and in abilities acquired during tumor progression as chemoresistance. The establishment of a pro-oxidant microenvironment also contributes to melanoma progression, implicating inflammatory cells as essential sources of ROS. Many mechanisms are associated with ROS accumulation in melanoma cells, including mitochondria dysfunction, increased NADPH oxidase activity and NOS uncoupling. ROS are implicated in regulating several biological processes by acting downstream important signaling pathways. Moreover, ROS regulate gene expression by genetic and epigenetic alterations. Although ROS are implicated in all stages of melanocyte malignant transformation, the uses of antioxidants as therapeutic strategies have not been successful. However, its use as a chemopreventive strategy has been shown to be efficient. Hence, efforts should be concentrated in the studies of the use of antioxidants as chemopreventive drugs for melanoma.

\section{Acknowledgements}

This work was supported by FAPESP (2011/12306-1 to MGJ and 2008/50366-3 to FM) and CAPES (2867/10 to FHMM).

\section{Author details}

Fabiana Henriques Machado de Melo ${ }^{1,2}$, Fernanda Molognoni ${ }^{2}$ and Miriam Galvonas Jasiulionis ${ }^{2^{*}}$

*Address all correspondence to: mjasiulionis@gmail.com

1 Microbiology, Immunology and Parasitology Department, Universidade Federal de São Paulo, São Paulo, Brazil

2 Pharmacology Department, Universidade Federal de São Paulo, São Paulo, Brazil 


\section{References}

[1] Fruehauf, J. P. Meyskens FL Jr. Reactive oxygen species: a breath of life or death? Clin Cancer Res. (2007). , 13(3), 789-94.

[2] Kabuyama, Y, Homma, M. K, Sekimata, M, \& Homma, Y. Wavelength-specific activation of MAP kinase family proteins by monochromatic UV irradiation. Photochem Photobiol (2001). , 73(2), 147-52.

[3] Brar, S. S, Kennedy, T. P, Whorton, A. R, Sturrock, A. B, Huecksteadt, T. P, Ghio, A. J, \& Hoidal, J. R. Reactive oxygen species from NAD(P)H:quinone oxidoreductase constitutively activate NF-kappaB in malignant melanoma cells. Am J Physiol Cell Physiol (2001). C, 659-76.

[4] Hussein, M. R. Ultraviolet radiation and skin cancer: molecular mechanisms. J Cutan Pathol (2005). , 32(3), 191-205.

[5] Ueda, Y, \& Richmond, A. NF-kappaB activation in melanoma. Pigment Cell Res (2006). , 19(2), 112-24.

[6] Xanthoudakis, S, Miao, G, Wang, F, Pan, Y. C, \& Curran, T. Redox activation of FosJun DNA binding activity is mediated by a DNA repair enzyme. EMBO J (1992). , 11(9), 3323-35.

[7] Smeal, T, Binetruy, B, Mercola, D. A, Birrer, M, \& Karin, M. Oncogenic and transcriptional cooperation with Ha-Ras requires phosphorylation of c-Jun on serines 63 and 73. Nature (1991). , 354(6353), 494-6.

[8] Ray, P. D, Huang, B. W, \& Tsuji, Y. Reactive oxygen species (ROS) homeostasis and redox regulation in cellular signaling. Cell Signal. (2012). May;, 24(5), 981-90.

[9] Govindarajan, B, Sligh, J. E, Vincent, B. J, Li, M, Canter, J. A, Nickoloff, B. J, Rodenburg, R. J, Smeitink, J. A, Oberley, L, Zhang, Y, Slingerland, J, Arnold, R. S, Lambeth, J. D, Cohen, C, Hilenski, L, Griendling, K, Martínez-diez, M, Cuezva, J. M, \& Arbiser, J. L. Overexpression of Akt converts radial growth melanoma to vertical growth melanoma. J Clin Invest (2007). , 117(3), 719-29.

[10] Cardounel, A. J, Xia, Y, \& Zweier, J. L. Endogenous methylarginines modulate superoxide as well as nitric oxide generation from neuronal nitric-oxide synthase: differences in the effects of monomethyl- and dimethylarginines in the presence and absence of tetrahydrobiopterin. J Biol Chem (2005). , 280(9), 7540-9.

[11] Rabelink, T. J, \& Luscher, T. F. Endothelial nitric oxide synthase: host defense enzyme of the endothelium? Arterioscler Thromb Vasc Biol (2006). , 26(2), 267-71.

[12] Melo, F. H, Molognoni, F, Morais, A. S, Toricelli, M, Mouro, M. G, Higa, E. M, Lopes, J. D, \& Jasiulionis, M. G. Endothelial nitric oxide synthase uncoupling as a key medi- 
ator of melanocyte malignant transformation associated with sustained stress conditions. Free Radic Biol Med (2011). , 50(10), 1263-73.

[13] Pervaiz, S, Ramalingam, J. K, Hirpara, J. L, \& Clément, M. V. Superoxide anion inhibits drug-induced tumor cell death. FEBS Lett. (1999). Oct 15;, 459(3), 343-8.

[14] Jensen, J. D, Wing, G. J, \& Dellavalle, R. P. Nutrition and melanoma prevention. Clin Dermatol. (2010). Nov-Dec; , 28(6), 644-9.

[15] Jang, M, Cai, L, Udeani, G. O, Slowing, K. V, Thomas, C. F, Beecher, C. W, Fong, H. H, Farnsworth, N. R, Kinghorn, A. D, Mehta, R. G, Moon, R. C, \& Pezzuto, J. M. Cancer chemopreventive activity of resveratrol, a natural product derived from grapes. Science (1997). , 275(5297), 218-20.

[16] Lao, C. D, Demierre, M. F, \& Sondak, V. K. Targeting events in melanoma carcinogenesis for the prevention of melanoma. Expert Rev Anticancer Ther (2006). , 6(11), 1559-68.

[17] Dröge, W. Free radicals in the physiological control of cell function. Physiol Rev. (2002). Jan; 82(1), 47-95.

[18] Valko, M, Leibfritz, D, Moncol, J, Cronin, M. T, Mazur, M, \& Telser, J. Free radicals and antioxidants in normal physiological functions and human disease. Int J Biochem Cell Biol. (2007). , 9(1), 44-84.

[19] Valko, M, Rhodes, C. J, Moncol, J, Izakovic, M, \& Mazur, M. Free radicals, metals and antioxidants in oxidative stress-induced cancer. Chem Biol Interact. (2006). Mar 10; 160(1), 1-40.

[20] Kang, J, \& Pervaiz, S. Mitochondria: redox metabolism and dysfunction. Biochem Res. Int. 2012;(2012).

[21] Muller, F. L, Liu, Y, \& Van Remmen, H. Complex III releases superoxide to both sides of the inner mitochondrial membrane. J Biol Chem. (2004). Nov 19;, 9(47), 49064-73.

[22] Altenhöfer, S, Kleikers, P. W, Radermacher, K. A, \& Scheurer, P. Rob Hermans JJ, Schiffers P, Ho H, Wingler K, Schmidt HH. The NOX toolbox: validating the role of NADPH oxidases in physiology and disease. Cell Mol Life Sci. (2012). Jul;, 69(14), 2327-43.

[23] Lassègue, B. San Martín A, Griendling KK. Biochemistry, physiology, and pathophysiology of NADPH oxidases in the cardiovascular system. Circ Res. (2012). May $11 ; 110(10), 1364-90$.

[24] Valko, M, Izakovic, M, Mazur, M, Rhodes, C. J, \& Telser, J. Role of oxygen radicals in DNA damage and cancer incidence. Mol Cell Biochem. (2004). Nov;266(1-2):37-56. 
[25] Sander, C. S, Chang, H, Hamm, F, Elsner, P, \& Thiele, J. J. Role of oxidative stress and the antioxidant network in cutaneous carcinogenesis. Int J Dermatol. (2004). May; 43(5), 326-35.

[26] Yen, H. C, Li, S. H, Majima, H. J, Huang, Y. H, Chen, C. P, Liu, C. C, Tu, Y. C, \& Chen, C. W. Up-regulation of antioxidant enzymes and coenzyme $Q(10)$ in a human oral cancer cell line with acquired bleomycin resistance. Free Radic Res. (2011). Jun; 45(6), 707-16.

[27] Policastro, L. L, Ibañez, I. L, Notcovich, C, Durán, H. A, \& Podhajcer, O. L. The tumor microenvironment: characterization, redox considerations and novel approaches for ROS-targeted gene therapy. Antioxid Redox Signal. (2012). Jul 15.

[28] Zelko, I. N, Mariani, T. J, \& Folz, R. J. Superoxide dismutase multigene family: a comparison of the CuZn-SOD (SOD1), Mn-SOD (SOD2), and EC-SOD (SOD3) gene structures, evolution, and expression. Free Radic Biol Med. (2002). , 33(3), 337-49.

[29] Circu, M. L, \& Aw, T. Y. Reactive oxygen species, cellular redox systems, and apoptosis. Free Radic Biol Med. (2010). Mar 15; 48(6), 749-62.

[30] Kulak, M. V, Cyr, A. R, Woodfield, G. W, Bogachek, M, Spanheimer, P. M, Li, T, Price, D. H, Domann, F. E, \& Weigel, R. J. Transcriptional regulation of the GPX1 gene by TFAP2C and aberrant CpG methylation in human breast cancer. Oncogene. (2012). Sep 10.

[31] Ansenberger-fricano, K. Silva Ganini DD, Mao M, Chatterjee S, Dallas S, Mason RP, Stadler K, Santos JH, Bonini MG. The peroxidase activity of mitochondrial superoxide dismutase. Free Radic Biol Med. (2012). Aug 28.

[32] Pastore, A, Federici, G, Bertini, E, \& Piemonte, F. Analysis of glutathione: implication in redox and detoxification. Clin Chim Acta. (2003). Jul 1; 333(1), 19-39.

[33] Lu, S. C. Regulation of glutathione synthesis. Mol Aspects Med. (2009). Feb-Apr; 30(1-2):42-59.

[34] Wood, Z. A, Poole, L. B, \& Karplus, P. A. Peroxiredoxin evolution and the regulation of hydrogen peroxide signaling. Science. (2003). Apr 25; 300(5619), 650-3.

[35] Meyer, Y, Buchanan, B. B, Vignols, F, \& Reichheld, J. P. Thioredoxins and glutaredoxins:unifying elements in redox biology. Annu Rev Genet. (2009). , 43, 335-67.

[36] Liu, H, Colavitti, R, Rovira, I. I, \& Finkel, T. Redox-dependent transcriptional regulation. Circ Res. (2005). Nov 11; 97(10), 967-74.

[37] Liu, G. S, Peshavariya, H, Higuchi, M, Brewer, A. C, Chang, C. W, Chan, E. C, \& Dusting, G. J. Microphthalmia-associated transcription factor modulates expression of NADPH oxidase type 4: a negative regulator of melanogenesis. Free Radic Biol Med. (2012). May 1;, 52(9), 1835-43.

[38] Campos, A. C, Molognoni, F, Melo, F. H, Galdieri, L. C, Carneiro, C. R, Almeida, D, Correa, V, \& Jasiulionis, M. MG. Oxidative stress modulates DNA methylation dur- 
ing melanocyte anchorage blockade associated with malignant transformation. Neoplasia (2007). , 9(12), 1111-21.

[39] Kumar, B, Koul, S, Khandrika, L, Meacham, R. B, \& Koul, H. K. Oxidative stress is inherent in prostate cancer cells and is required for aggressive phenotype. Cancer Res. (2008). Mar 15; 68(6), 1777-85.

[40] Pani, G, Galeotti, T, \& Chiarugi, P. Metastasis: cancer cell's escape from oxidative stress. Cancer Metastasis Rev. (2010). Jun;, 29(2), 351-78.

[41] Hanahan, D, \& Weinberg, R. A. Hallmarks of cancer: the next generation. Cell. (2011). Mar 4;, 144(5), 646-74.

[42] Meyskens FL JrMcNulty SE, Buckmeier JA, Tohidian NB, Spillane TJ, Kahlon RS, Gonzalez RI. Aberrant redox regulation in human metastatic melanoma cell compared to normal melanocytes. Free Radic Biol Med. (2001). Sep 15;, 31(6), 799-808.

[43] Handa, O, Naito, Y, \& Yoshikawa, T. Helicobacter pylori: a ROS-inducing bacterial species in the stomach. Inflamm Res. (2010). Dec;, 59(12), 997-1003.

[44] Hole, P. S, Darley, R. L, \& Tonks, A. Do reactive oxygen species play a role in myeloid leukemias? Blood. (2011). Jun 2;, 117(22), 5816-26.

[45] Saxena, A, Tammali, R, Ramana, K. V, \& Srivastava, S. K. Aldose reductase inhibition prevents colon cancer growth by restoring PTEN through modulation of miR-21 and FOXO3a. Antioxid Redox Signal. (2012). Sep 16.

[46] Vurusaner, B, Poli, G, \& Basaga, H. Tumor suppressor genes and ROS: complex networks of interactions. Free Radic Biol Med. (2012). Jan 1;, 52(1), 7-18.

[47] Dolado, I, Swat, A, Ajenjo, N, De Vita, G, Cuadrado, A, \& Nebreda, A. R. p. alpha MAP kinase as a sensor of reactive oxygen species in tumorigenesis. Cancer Cell. (2007). Feb;PubMed PMID: 17292829., 11(2), 191-205.

[48] Chan, D. W, Liu, V. W, Tsao, G. S, Yao, K. M, Furukawa, T, Chan, K. K, \& Ngan, H. $\mathrm{Y}$. Loss of MKP3 mediated by oxidative stress enhances tumorigenicity and chemoresistance of ovarian cancer cells. Carcinogenesis. (2008). Sep;, 29(9), 1742-50.

[49] Ambrus, C. M, Lajos, T. Z, Stadler, I, Stadler, A, Alfano, J, \& Tulumello, J. A. Ambrus Jr. Myocardial release of non-transferrin-bound iron during cardio-pulmonary bypass surgery. J Med. (1999). , 30(3), 4-157.

[50] Franco, R, Schoneveld, O, Georgakilas, A. G, \& Panayiotidis, M. I. Oxidative stress, DNA methylation and carcinogenesis. Cancer Lett. (2008). Jul 18;, 266(1), 6-11.

[51] Marnett, L. J. Oxyradicals and DNA damage. Carcinogenesis. (2000). Mar;”21(3), $361-70$.

[52] Valinluck, V, Tsai, H. H, Rogstad, D. K, Burdzy, A, Bird, A, \& Sowers, L. C. Oxidative damage to methyl-CpG sequences inhibits the binding of the methyl-CpG bind- 
ing domain (MBD) of methyl-CpG binding protein 2 (MeCP2). Nucleic Acids Res (2004). , 32(14), 4100-8.

[53] Maltseva, D. V, Baykov, A. A, Jeltsch, A, \& Gromova, E. S. Impact of 7,8-dihydro-8oxoguanine on methylation of the CpG site by Dnmt3a. Biochemistry (2009). , 48(6), 1361-8.

[54] Hagan, O, Wang, H. M, Sen, W, Destefano, S, Shields, C, Lee, S. S, Zhang, Y. W, Clements, E. G, Cai, Y, Van Neste, L, Easwaran, H, Casero, R. A, \& Sears, C. L. Baylin SB. Oxidative damage targets complexes containing DNA methyltransferases, SIRT1, and polycomb members to promoter CpG Islands. Cancer Cell. (2011). Nov 15; 20(5), 606-19.

[55] Escobar, J, Pereda, J, López-rodas, G, \& Sastre, J. Redox signaling and histone acetylation in acute pancreatitis. Free Radic Biol Med. (2012). Mar 1;, 52(5), 819-37.

[56] Irani, K, Xia, Y, Zweier, J. L, \& Sollott, S. J. Der CJ, Fearon ER, Sundaresan M, Finkel T, Goldschmidt-Clermont PJ. Mitogenic signaling mediated by oxidants in Ras transformed fibroblasts. Science. (1997). Mar 14;, 275(5306), 1649-52.

[57] Yamaura, M, Mitsushita, J, Furuta, S, Kiniwa, Y, Ashida, A, Goto, Y, Shang, W. H, Kubodera, M, Kato, M, Takata, M, Saida, T, \& Kamata, T. NADPH oxidase 4 contributes to transformation phenotype of melanoma cells by regulating G2-M cell cycle progression. Cancer Res (2009). , 69(6), 2647-54.

[58] Mitsushita, J, Lambeth, J. D, \& Kamata, T. The superoxide-generating oxidase Nox1 I functionally required for Ras oncogene transformation. Cancer Res (2004). , 64, 3580-3585.

[59] Weinberg, F, Hamanaka, R, Wheaton, W. W, Weinberg, S, Joseph, J, Lopez, M, Kalyanaraman, B, Mutlu, G. M, Budinger, G. R, \& Chandel, N. S. Mitochondrial metabolism and ROS generation are essential for Kras-mediated tumorigenicity. Proc Natl Acad Sci U S A. (2010). May 11; 107(19), 8788-93.

[60] Pervaiz, S, \& Clement, M. V. Superoxide anion: oncogenic reactive oxygen species? Int J Biochem Cell Biol. (2007).

[61] Church, S, Grant, J, Ridnour, L. A, Oberley, L. W, Swanson, P. E, Meltzer, P. S, \& Trent, J. M. Increased manganese superoxide dismutase expression suppresses the malignant phenotype of human melanoma cells. Proc Natl Acad Sci U S A. (1993). Apr $1 ;$, 90(7), 3113-7.

[62] Weydert, C, Roling, B, Liu, J, Hinkhouse, M. M, Ritchie, J. M, Oberley, L. W, \& Cullen, J. J. Suppression of the malignant phenotype in human pancreatic cancer cells by the overexpression of manganese superoxide dismutase. Mol Cancer Ther. (2003). Apr;, 2(4), 361-9.

[63] Venkataraman, S, Jiang, X, Weydert, C, Zhang, Y, Zhang, H. J, Goswami, P. C, Ritchie, J. M, Oberley, L. W, \& Buettner, G. R. Manganese superoxide dismutase overex- 
pression inhibits the growth of androgen-independent prostate cancer cells. Oncogene. (2005). Jan 6;, 24(1), 77-89.

[64] Low, I. C, Kang, J, \& Pervaiz, S. Bcl-2: a prime regulator of mitochondrial redox metabolism in cancer cells. Antioxid Redox Signal. (2011). Dec 15;, 15(12), 2975-87.

[65] Von Thaler, A. K, Kamenisch, Y, \& Berneburg, M. The role of ultraviolet radiation in melanomagenesis. Exp Dermatol. (2010). , 19(2), 81-8.

[66] West, X. Z, Malinin, N. L, Merkulova, A. A, Tischenko, M, Kerr, B. A, Borden, E. C, Podrez, E. A, Salomon, R. G, \& Byzova, T. V. Oxidative stress induces angiogenesis by activating TLR2 with novel endogenous ligands. Nature. (2010). Oct 21; 467(7318), 972-6.

[67] Meyskens FL JrChau HV, Tohidian N, Buckmeier J. Luminol-enhanced chemiluminescent response of human melanocytes and melanoma cells to hydrogen peroxide stress. Pigment Cell Res. (1997). Jun;, 10(3), 184-9.

[68] Borrello, S, De Leo, M. E, \& Galeotti, T. Defective gene expression of MnSOD in cancer cells. Mol Aspects Med. (1993). , 14(3), 253-8.

[69] Picardo, M, Maresca, V, Eibenschutz, L, De Bernardo, C, Rinaldi, R, \& Grammatico, P. Correlation between antioxidants and phototypes in melanocytes cultures. A possible link of physiologic and pathologic relevance. J Invest Dermatol. (1999). Sep; 113(3), 424-5.

[70] Gidanian, S, \& Mentelle, M. Meyskens FL Jr, Farmer PJ. Melanosomal damage in normal human melanocytes induced by UVB and metal uptake--a basis for the pro-oxidant state of melanoma. Photochem Photobiol. (2008). May-Jun;, 84(3), 556-64.

[71] Armstrong, B. K, \& Kricker, A. The epidemiology of UV induced skin cancer. JPhotochem Photobiol B (2001).

[72] Tadokoro, T, Kobayashi, N, Zmudzka, B. Z, Ito, S, Wakamatsu, K, Yamaguchi, Y, Korossy, K. S, Miller, S. A, Beer, J. Z, \& Hearing, V. J. UV-induced DNA damage and melanin content in human skin differing in racial/ethnic origin. FASEB J (2003). , 17(9), 1177-9.

[73] Wood, S. R, Berwick, M, Ley, R. D, Walter, R. B, Setlow, R. B, \& Timmins, G. S. UV causation of melanoma in Xiphophorus is dominated by melanin photosensitized oxidant production. Proc Natl Acad Sci U S A (2006). , 103(11), 4111-5.

[74] Mukhtar, H, Forbes, P. D, \& Ananthaswamy, H. N. Photocarcinogenesis--models and mechanisms. Photodermatol Photoimmunol Photomed (1999).

[75] Horikawa-miura, M, Matsuda, N, Yoshida, M, Okumura, Y, Mori, T, \& Watanabe, M. The greater lethality of UVB radiation to cultured human cells is associated with the specific activation of a DNA damage-independent signaling pathway. Radiat Res (2007). , 167(6), 655-62. 
[76] Birch-machin, M. A, \& Swalwell, H. How mitochondria record the effects of UV exposure and oxidative stress using human skin as a model tissue. Mutagenesis (2010). , 25(2), 101-7.

[77] Cotter, M. A, Thomas, J, Cassidy, P, Robinette, K, Jenkins, N, Florell, S. R, Leachman, S, \& Samlowski, W. E. Grossman D. N-acetylcysteine protects melanocytes against oxidative stress/damage and delays onset of ultraviolet-induced melanoma in mice.Clin Cancer Res (2007). , 13(19), 5952-8.

[78] Bhushan, A, Abramson, R, Chiu, J. F, \& Tritton, T. R. Expression of c-fos in human and murine multidrug-resistant cells. Mol Pharmacol (1992). , 42(1), 69-74.

[79] Mishra, M. V, Bisht, K. S, Sun, L, Muldoon-jacobs, K, Awwad, R, Kaushal, A, Nguyen, P, Huang, L, Pennington, J. D, Markovina, S, Bradbury, C. M, \& Gius, D. DNMT1 as a molecular target in a multimodality-resistant phenotype in tumor cells. Mol Cancer Res (2008). , 6(2), 243-9.

[80] Ming, M, Han, W, Maddox, J, Soltani, K, Shea, C. R, Freeman, D. M, \& He, Y. Y. UVB-induced ERK/AKT-dependent PTEN suppression promotes survival of epidermal keratinocytes. Oncogene (2010). , 29(4), 492-502.

[81] Birck, A, Ahrenkiel, V, Zeuthen, J, Hou-jensen, K, \& Guldberg, P. Mutation and allelic loss of the PTEN/MMAC1 gene in primary and metastatic melanoma biopsies. J Invest Dermatol (2000). , 114(2), 277-80.

[82] Chudnovsky, Y, Adams, A. E, Robbins, P. B, Lin, Q, \& Khavari, P. A. Use of human tissue to assess the oncogenic activity of melanoma-associated mutations. Nat Genet (2005). , 37(7), 745-9.

[83] Mirmohammadsadegh, A, Marini, A, Nambiar, S, Hassan, M, Tannapfel, A, Ruzicka, T, \& Hengge, U. R. Epigenetic silencing of the PTEN gene in melanoma. Cancer Res (2006). , 66(13), 6546-52.

[84] Noonan, F. P, Dudek, J, Merlino, G, \& De Fabo, E. C. Animal models of melanoma: an HGF/SF transgenic mouse model may facilitate experimental access to UV initiating events. Pigment Cell Res (2003). , 16(1), 16-25.

[85] Larsson, P, Andersson, E, Johansson, U, Ollinger, K, Rosdahl, I, \& Ultraviolet, A. and $\mathrm{B}$ affect human melanocytes and keratinocytes differently. A study of oxidativealterations and apoptosis. Exp Dermatol (2005). , 14(2), 117-23.

[86] Swalwell, H, Latimer, J, Haywood, R. M, \& Birch-machin, M. A. Investigating the role of melanin in UVA/UVB- and hydrogen peroxide-induced cellular and mitochondrial ROS production and mitochondrial DNA damage in human melanoma cells. Free Radic Biol Med (2012). , 52(3), 626-34.

[87] Warren, J. B, Loi, R. K, \& Coughlan, M. L. Involvement of nitric oxide synthase in the delayed vasodilator response to ultraviolet light irradiation of rat skin in vivo. Br J Pharmacol. (1993). Jul;; 109(3), 802-6. 
[88] Kuhn, A, Fehsel, K, Lehmann, P, Krutmann, J, Ruzicka, T, \& Kolb-bachofen, V. Aberrant timing in epidermal expression of inducible nitric oxide synthase after UV irradiation in cutaneous lupus erythematosus. J Invest Dermatol (1998). , 111(1), 149-53.

[89] Suschek, C. V, Bruch-gerharz, D, Kleinert, H, Förstermann, U, Kolb-bachofen, V, \& Ultraviolet, A. radiation induces nitric oxide synthase-2 expression in human skin endothelial cells in the absence of proinflammatory cytokines. J Invest Dermatol 2001; Channon KM. Tetrahydrobiopterin: regulator of endothelial nitric oxide synthase in vascular disease. Trends Cardiovasc Med (2004). , 117(5), 1200-5.

[90] Hink, U, Li, H, Mollnau, H, Oelze, M, Matheis, E, Hartmann, M, Skatchkov, M, Thaiss, F, Stahl, R. A, Warnholtz, A, Meinertz, T, Griendling, K, Harrison, D. G, Forstermann, U, \& Munzel, T. Mechanisms underlying endothelial dysfunction in diabetes mellitus. Circ Res. (2001). E, 14-22.

[91] Roe, N. D, \& Ren, J. Nitric oxide synthase uncoupling: A therapeutic target in cardiovascular diseases. Vascul Pharmacol (2012). Feb 16.

[92] Teixeira, M. M, Williams, T. J, \& Hellewell, P. G. Role of prostaglandins and nitric oxide in acute inflammatory reactions in guinea-pig skin. Br J Pharmacol (1993). , $110(4), 1515-21$.

[93] Creppy, E. E, Traoré, A, Baudrimont, I, Cascante, M, \& Carratú, M. R. Recent advances in the study of epigenetic effects induced by the phycotoxin okadaic acid. Toxicology (2002).

[94] Hitchler, M. J, \& Domann, F. E. An epigenetic perspective on the free radical theory of development. Free Radic Biol Med (2007). , 43(7), 1023-36.

[95] Lechner, M, Lirk, P, \& Rieder, J. Inducible nitric oxide synthase (iNOS) in tumor biology: the two sides of the same coin. Semin Cancer Biol (2005). , 15(4), 277-89.

[96] Schwarz, T. Photoimmunosuppression. Photodermatol Photoimmunol Photomed (2002). , 18(3), 141-5.

[97] Kanavy, H. E, \& Gerstenblith, M. R. Ultraviolet radiation and melanoma. Semin Cutan Med Surg (2011). , 30(4), 222-8.

[98] Yuen, K. S, Nearn, M. R, \& Halliday, G. M. Nitric oxide-mediated depletion of Langerhans cells from the epidermis may be involved in UVA radiation-induced immunosuppression. Nitric Oxide (2002). , 6(3), 313-8.

[99] Brar, S. S, Kennedy, T. P, Sturrock, A. B, Huecksteadt, T. P, Quinn, M. T, Whorton, A. $\mathrm{R}$, \& Hoidal, J. R. An NAD(P)H oxidase regulates growth and transcription in melanoma cells. Am J Physiol Cell Physiol (2002). C, 1212-24.

[100] Liu, F. Gomez Garcia AM, Meyskens FL Jr. NADPH Oxidase 1 OverexpressionEnhances Invasion via Matrix Metalloproteinase-2 and Epithelial-MesenchymalTransition in Melanoma Cells. J Invest Dermatol (2012). , 132(8), 2033-41. 
[101] Barbi de Moura MVincent G, Fayewicz SL, Bateman NW, Hood BL, Sun M, Suhan J, Duensing S, Yin Y, Sander C, Kirkwood JM, Becker D, Conrads TP, Van Houten B, Moschos SJ. Mitochondrial respiration- an important therapeutic target in melanoma. PLoS One. (2012). e40690.

[102] Warburg, O. On the origin of cancer cells. Science. (1956). Feb 24; 123(3191), 309-14.

[103] Kallinowski, F, Schlenger, K. H, Runkel, S, Kloes, M, Stohrer, M, Okunieff, P, \& Vaupel, P. Blood flow, metabolism, cellular microenvironment, and growth rate of human tumor xenografts. Cancer Res. (1989). Jul 15;, 49(14), 3759-64.

[104] Scott, D. A, Richardson, A. D, Filipp, F. V, Knutzen, C. A, Chiang, G. G, Ronai, Z. A, Osterman, A. L, \& Smith, J. W. Comparative metabolic flux profiling of melanoma cell lines: beyond the Warburg effect. J Biol Chem. (2011). Dec 9;, 286(49), 42626-34.

[105] Hersey, P, Watts, R. N, Zhang, X. D, \& Hackett, J. Metabolic approaches to treatment of melanoma. Clin Cancer Res. (2009). Nov 1; 15(21), 6490-4.

[106] Manola, J, Atkins, M, Ibrahim, J, \& Kirkwood, J. Prognostic factors in metastatic melanoma: a pooled analysis of Eastern Cooperative Oncology Group trials. J Clin Oncol. (2000). Nov 15; 18(22), 3782-93.

[107] Gidanian, S, \& Mentelle, M. Meyskens FL Jr, Farmer PJ. Melanosomal damage in normal human melanocytes induced by UVB and metal uptake--a basis for the pro-oxidant state of melanoma. Photochem Photobiol. (2008). May-Jun;, 84(3), 556-64.

[108] Sarangarajan, R, \& Apte, S. P. The polymerization of melanin: a poorly understood phenomenon with egregious biological implications. Melanoma Res. (2006). Feb; 16(1), 3-10.

[109] Hearing, V. J. Determination of melanin synthetic pathways. J Invest Dermatol. (2011). Nov 17;131(E1):EE11., 8.

[110] Rhodes, A. R, Seki, Y, Fitzpatrick, T. B, \& Stern, R. S. Melanosomal alterations in dysplastic melanocytic nevi. A quantitative, ultrastructural investigation. Cancer. (1988). Jan $15 ;$, 61(2), 358-69.

[111] Wittgen, H. G, \& Van Kempen, L. C. Reactive oxygen species in melanoma and its therapeutic implications. Melanoma Res. (2007). Dec;, 17(6), 400-9.

[112] Pavel, S, Van Nieuwpoort, F, Van Der Meulen, H, Out, C, Pizinger, K, Cetkovská, P, Smit, N. P, \& Koerten, H. K. Disturbed melanin synthesis and chronic oxidative stress in dysplastic naevi. Eur J Cancer. (2004). Jun;, 40(9), 1423-30.

[113] Farmer, P. J, Gidanian, S, \& Shahandeh, B. Di Bilio AJ, Tohidian N, Meyskens FL Jr. Melanin as a target for melanoma chemotherapy: pro-oxidant effect of oxygen and metals on melanoma viability. Pigment Cell Res. (2003). Jun;, 16(3), 273-9.

[114] Meyskens FL JrFarmer PJ, Yang S, Anton-Culver H. New perspectives on melanoma pathogenesis and chemoprevention. Recent Results Cancer Res. (2007). , 174, 191-5. 
[115] Leonard, S. S, Harris, G. K, \& Shi, X. Metal-induced oxidative stress and signal transduction. Free Radic Biol Med. (2004). Dec 15;, 37(12), 1921-42.

[116] Bertolotto, C, Abbe, P, Hemesath, T. J, Bille, K, Fisher, D. E, Ortonne, J. P, \& Ballotti, R. Microphthalmia gene product as a signal transducer in cAMP-induced differentiation of melanocytes. J Cell Biol. (1998). Aug 10;, 142(3), 827-35.

[117] Barbieri, A, Palma, G, Rosati, A, Giudice, A, Falco, A, Petrillo, A, Petrillo, M, \& Bimonte, S. Di Benedetto M, Esposito G, Stiuso P, Abbruzzese A, Caraglia M, Arra C. Role of endothelial nitric oxide synthase (eNOS) in chronic stress-promoted tumour growth. J Cell Mol Med. (2012). Apr;; 16(4), 920-6.

[118] Salvucci, O, Carsana, M, Bersani, I, Tragni, G, \& Anichini, A. Antiapoptotic role of endogenous nitric oxide in human melanoma cells. Cancer Res. (2001). Jan 1;,61(1), $318-26$.

[119] Ellerhorst, J. A, et al. Regulation of iNOS by the mitogen-activated protein kinase pathway in human melanoma. Oncogene. (2006). Jun 29; 25(28):3956-62., 44.

[120] Lim, K. H, Ancrile, B. B, Kashatus, D. F, \& Counter, C. M. Tumour maintenance is mediated by eNOS. Nature. (2008). Apr 3; 452(7187), 646-9.

[121] Lampson, B. L, Kendall, S. D, Ancrile, B. B, Morrison, M. M, Shealy, M. J, Barrientos, K. S, Crowe, M. S, Kashatus, D. F, White, R. R, Gurley, S. B, Cardona, D. M, \& Counter, C. M. Targeting eNOS in pancreatic cancer. Cancer Res. (2012). Sep 1; 72(17), 4472-82.

[122] Oba-shinjo, S. M, Correa, M, Ricca, T. I, Molognoni, F, Pinhal, M. A, Neves, I. A, Marie, S. K, Sampaio, L. O, Nader, H. B, Chammas, R, \& Jasiulionis, M. G. Melanocyte transformation associated with substrate adhesion impediment. Neoplasia. (2006). Mar;, 8(3), 231-41.

[123] Yang, S, Misner, B. J, \& Chiu, R. J. Meyskens FL Jr. Redox effector factor-1, combined with reactive oxygen species, plays an important role in the transformation of JB6 cells. Carcinogenesis. (2007). Nov;, 28(11), 2382-90.

[124] Yang, S, Irani, K, Heffron, S. E, \& Jurnak, F. Meyskens FL Jr. Alterations in the expression of the apurinic/apyrimidinic endonuclease-1/redox factor-1 (APE/Ref-1) in human melanoma and identification of the therapeutic potential of resveratrol as an APE/Ref-1 inhibitor. Mol Cancer Ther. (2005). Dec;" 4(12), 1923-35.

[125] Yang, S, \& Meyskens, F. L. Apurinic/apyrimidinic endonuclease/redox effector factor-1(APE/Ref-1): a unique target for the prevention and treatment of human melanoma. Antioxid Redox Signal. (2009). Mar;, 11(3), 639-50.

[126] Palmieri, G, Capone, M, Ascierto, M. L, Gentilcore, G, Stroncek, D. F, Casula, M, Sini, M. C, Palla, M, Mozzillo, N, \& Ascierto, P. A. Main roads to melanoma. J Transl Med. (2009). Oct 14;7:86. 
[127] Jenkins, N. C, Liu, T, Cassidy, P, Leachman, S. A, Boucher, K. M, Goodson, A. G, Samadashwily, G, Grossman, D, \& The, p. INK4A) tumor suppressor regulates cellular oxidative stress. Oncogene. (2011). Jan 20;, 30(3), 265-74.

[128] Selimovic, D, Hassan, M, Haikel, Y, \& Hengge, U. R. Taxol-induced mitochondrial stress in melanoma cells is mediated by activation of c-Jun N-terminal kinase (JNK) and pathways via uncoupling protein 2. Cell Signal. (2008). Feb;20(2):311-22., 38.

[129] Lee, S, Kim, Y. K, Shin, T. Y, \& Kim, S. H. Neurotoxic Effects of Bisphenol AF on Calcium-Induced ROS and MAPKs. Neurotox Res. (2012). Sep 21.

[130] Oberlay, T. D, \& Oberlay, L. W. Antioxidant enzyme levels in cancer. Histol Histopathol. (1997). , 12, 525-535.

[131] Yohn, J, Norris, D, Yrastorza, D, Bruno, I, Leff, J, Hake, S, \& Repine, J. Disparate antioxidant enzyme activities in cultured cutaneous fibroblasts, keratinocytes and melanocytes. J Invest Dermatol. (1991). , 97, 405-410.

[132] Maxwell, S. R. Prospects for the use of antioxidant therapies. Drugs (1995). , 49, $345-61$.

[133] Agostini, D, Balansky, F, Camoirano, R. M, \& De Flora, A. S. Modulation of light-induced skin tumors by $\mathrm{N}$-acetylcisteine and/or ascorbic acid in hairless mice. Carcinogenesis (2005). , 26, 657-64.

[134] Cotter, M. A, Thomas, J, Cassidy, P, Robinette, K, Jenkins, N, Florell, S. R, Leachman, S, \& Samlowski, W. E. Grossman D. N-acetylcysteine protects melanocytes against oxidative stress/damage and delays onset of ultraviolet-induced melanoma in mice. Clin Cancer Res. (2007). Oct 1; 13(19), 5952-8.

[135] Goodson, A. G, Cotter, M. A, Cassidy, P, Wade, M, Florell, S. R, Liu, T, Boucher, K. M, \& Grossman, D. Use of oral N-acetylcysteine for protection of melanocytic nevi against UV-induced oxidative stress: towards a novel paradigm for melanoma chemoprevention. Clin Cancer Res. (2009). Dec 1; 15(23), 7434-40.

[136] Kang, S, Chung, J. H, Lee, J. H, et al. Topical N-acetylcysteine and genistein prevent ultraviolet-light-induced signaling that leads to photoaging in human skin in vivo. J Invest Dermatol (2003). , 120, 835-41.

[137] Ichihashi, M, Ahmed, N. U, Budiyanto, A, Wu, A, Bito, T, Ueda, M, \& Osawa, T. Preventive effect of antioxidant on ultraviolet-induced skin cancer in mice. J Dermatol Sci (2000). S, 45-50.

[138] Kundu, J. K, Chun, K. S, Kim, S. O, \& Surh, Y. J. Resveratrol inhibits phorbol esterinduced cyclooxygenase-2 expression in mouse skin: MAPKs and AP-1 as potential molecular targets. Biofactors. (2004).

[139] Luo, M, Delaplane, S, Jiang, A, Reed, A, He, Y, Fishel, M, \& Nyland, R. L. nd, Borch RF, Qiao X, Georgiadis MM, Kelley MR. Role of the multifunctional DNA repair and redox signaling protein Ape1/Ref-1 in cancer and endothelial cells: small-molecule 
inhibition of the redox function of Ape1. Antioxid Redox Signal. (2008). Nov; 10(11), 1853-67.

[140] Fishel, M. L, Colvin, E. S, Luo, M, Kelley, M. R, \& Robertson, K. A. Inhibition of the redox function of APE1/Ref-1 in myeloid leukemia cell lines results in a hypersensitive response to retinoic acid-induced differentiation and apoptosis. Exp Hematol. (2010). Dec;, 38(12), 1178-88. 
